\title{
Use of off-label and unlicensed drugs in pediatric patients: A longitudinal prevalence survey from Lahore, Pakistan
}

\author{
Muhammad Hafeez ${ }^{1}$, Nadeem Irfan Bukhari ${ }^{1}$, Nasir Abbas ${ }^{1}$, Khalid Hussain ${ }^{1}$, \\ Amjad Hussain ${ }^{1}$, Zikria Saleem ${ }^{1,2 \star}$ \\ ${ }^{1}$ University College of Pharmacy, University of the Punjab, Lahore, Pakistan, ${ }^{2}$ School of Pharmaceutical Sciences, Universiti \\ Sains Malaysia, Malaysia
}

*For correspondence: Email: nadeem_irfan@hotmail.com; Tel: +92-300-4259738

\begin{abstract}
Purpose: To assess the extent of use of unlicensed/off-label drug in the children hospitalized in The Children's Hospital and Institute of Child Health, Lahore, Pakistan.

Methods: A prospective prevalence study was carried out in the selected hospital. A total of 1946 pediatric patients were hospitalized during study period. The patients' demographic data and unlicensed/off-label drug use were noted by the researcher using a structured questionnaire and then analyzed.

Results: During the survey period, 102 (5.24 \%) pediatric patients received at least one off-label drug/unlicensed drug. The unlicensed drug was administered to 65 patients (63.7\%) while off-label drug was administered to 37 patients (36.3\%). Milrinone (23.5\%) was the most frequently prescribed unlicensed drug.

Conclusion: The administration of unlicensed/off-label drug to treat different diseases in pediatric population is widespread in the health facility studied. These findings will provide guidance to new researchers in clinical trials, especially on cardiovascular drugs, opioid analgesic, antiemetic and anticancer drugs.
\end{abstract}

Keywords: Pediatric, Off-label drugs, Unlicensed drugs

\begin{abstract}
This is an Open Access article that uses a fund-ing model which does not charge readers or their institutions for access and distributed under the terms of the Creative Commons Attribution License (http://creativecommons.org/licenses/by/4.0) and the Budapest Open Access Initiative (http://www.budapestopenaccessinitiative.org/read), which permit unrestricted use, distribution, and reproduction in any medium, provided the original work is properly credited.

Tropical Journal of Pharmaceutical Research is indexed by Science Citation Index (SciSearch), Scopus, International Pharmaceutical Abstract, Chemical Abstracts, Embase, Index Copernicus, EBSCO, African Index Medicus, JournalSeek, Journal Citation Reports/Science Edition, Directory of Open Access Journals (DOAJ), African Journal Online, Bioline International, Open-J-Gate and Pharmacy Abstracts
\end{abstract}

\section{INTRODUCTION}

Many licensed drugs that are commercially available are used only for adults and are not utilized in pediatric practice in accordance with product licensing [1]. Moreover, available dosage forms of many drugs are not suitable for pediatrics [2]. Both prescription and over the counter drugs are used as off-label. Use of offlabel drugs are mostly considered as legal as long as it does not deviate the ethical guidelines or specifically safety measures, but it may have risk for health and have of legal liabilities [3]. In India, high prevalence of off-label drugs (50.6\%) has been reported in patients admitted in general pediatric units [4]. The off-label drug may be prescribed for pediatrics when there is no proper alternative drug available. 
The duty of Drug Regulatory Authority (DRA) is to set a policy concerning pre-marketing evaluation (overall benefit/risk evaluation) and marketing authorization or registration of the drugs [5]. Most of the medications used for pediatrics reportedly are off-label which does not fulfill the standard of safety and efficacy. Product licensing procedure was initiated in response to adverse drug reactions (ADRs) that not only appeared in adults but also in infants (Grey Baby Syndrome induced by Chloramphenicol) and developing fetus (Phocomelia induced by Thalidomide) [6]. Due to the scarcity of pediatric clinical data, off-label or unlicensed drugs are used widely around the globe. Insufficient pediatric clinical data may be due to lack of resources provided by administration, hesitancy of parents or guardians to permit their children to participate in clinical trials and other ethical problems of research in pediatrics.

Multisite studies reported the unlicensed/off-label drug utilization and prospective drug surveillance for side effects or adverse drug reactions (ADRs) in pediatric population [6-8]. It has also been reported that neonates and infants are frequently received drug as unlicensed/off-label in healthcare settings [9]. In Germany, offlabel/unlicensed drug was administered to $61 \%$ pediatrics hospitalized in general medicine pediatric wards [10]. In Brazil, a study of 272 pediatric patients of general medical wards, aged up to 16 years, recorded that about $22 \%$ of them received one unlicensed drug and $60 \%$ of them received a minimum of one off label drug during their stay in the university hospital [11]. The purpose of this study was to assess the use of unlicensed/off-label drug in hospitalized pediatric patients.

\section{METHODS}

A prospective prevalence study of unlicensed/offlabel drug use in pediatric patients was executed in The Children's Hospital and Institute of Child Health, Lahore. This hospital was selected because this is the largest pediatric hospital of Pakistan. This research was approved by Human Ethical Committee of University College of Pharmacy, Punjab University, Lahore (approval no. HEC/PUCP/1954) and Ethical Review Board of The Children's Hospital, Lahore (approval no. 8227). Off-label or unlicensed drugs used by pediatric population was identified using British National Formulary (BNF) [12]. All the patients admitted in the four selected wards such as, Cardiology, Diarrhea, General Surgery \& Gastroenterology of The Children's Hospital Lahore and at least one off-label or un-licensed drug prescribed were included in this study. The patients with unconfirmed diagnosis were excluded from this study.

This questionnaire was also approved by two pediatricians. The data collection included the following information: parent's profession and socioeconomic status, dietary status of patients, prescribed off-label and unlicensed drug associated with frequency, dose, and route of administration, condition of prescribing off label drug, co-morbidities, co-medications, use of any herbal drug, possible adverse drug reactions (ADRs) or side effects by the administration of these unlicensed and off label drugs and lab values of serological tests. The information of utilization of following drugs was not included: blood products, topical anesthetic creams, standard intravenous crystalloid solutions, oxygen therapy and total parenteral nutrition.

\section{Data collection and processing}

Prescription data of all admitted patients in selected pediatric wards during last 4 month period was evaluated. All prescriptions of unlicensed and off label drugs were collected and most commonly prescribed drugs were checked with the reference of British National Formulary. Patient's data regarding demographics and the unlicensed/off-label drug utilization were noted by the researcher himself from patient's treatment files. The data were categorized as infants, toddlers, preschoolers, early age schoolers, children and school age children. All the drugs were unlicensed and offlabel if they were prescribed beyond the recommendation meant for the age group. Event effects were monitored with the aid of package insert, BNF and standard books to determine the side effects/adverse drug reaction (ADR).

\section{RESULTS}

\section{Demographic characteristics}

A total of 1946 admitted patients in selected wards of the hospital met the inclusion criteria for this study during the study period. As indicated in Table 1, most of the patients belonged to early age school children $(29.4 \%)$ and infants $(28.3 \%)$ category. Out of total 102 patients, 66 were males and 36 were females.

\section{Unlicensed drug use with respect to different age groups and gender}

Unlicensed drugs were prescribed in $63.7 \%$ of total prescriptions (Table 2). Unlicensed prescribed drugs were more common in males (36.3\%) compared to females (27.4\%). Drugs 
Table 1: Division of patient numbers and prescriptions with different age groups

\begin{tabular}{|c|c|c|c|c|}
\hline $\begin{array}{l}\text { Age } \\
\text { category }\end{array}$ & $\begin{array}{l}\text { Age } \\
\text { (years) }\end{array}$ & $\begin{array}{l}\text { Total } \\
\text { N (\%) }\end{array}$ & $\begin{array}{l}\text { Male } \\
\text { N (\%) }\end{array}$ & $\begin{array}{l}\text { Female } \\
\mathrm{N}(\%)\end{array}$ \\
\hline Infant & $\leq 1$ & $\begin{array}{l}29 \\
(28.43)\end{array}$ & $21(20.6)$ & $8(7.8)$ \\
\hline Toddler & $1-3$ & $15(14.7)$ & $9(8.8)$ & $6(5.9)$ \\
\hline $\begin{array}{l}\text { Pre- } \\
\text { schoolers }\end{array}$ & $3-6$ & $17(16.6)$ & $10(9.8)$ & $7(6.8)$ \\
\hline $\begin{array}{l}\text { Early-age } \\
\text { school } \\
\text { children }\end{array}$ & $6-11$ & $30(29.4)$ & $17(16.7)$ & $13(12.7)$ \\
\hline $\begin{array}{l}\text { School } \\
\text { age } \\
\text { children }\end{array}$ & $11-15$ & $11(10.8)$ & $9(8.8)$ & $2(1.9)$ \\
\hline
\end{tabular}

Table 2: Categorization of prescriptions of off-label and unlicensed drugs with respect to age group and gender

\begin{tabular}{lcc}
\hline Variable & $\begin{array}{c}\text { Off Label (N } \\
\%)\end{array}$ & $\begin{array}{c}\text { Unlicensed (N } \\
\%)\end{array}$ \\
$\begin{array}{l}\text { Age group } \\
\text { Infant }\end{array}$ & $20(19.6)$ & $9(88)$ \\
Toddler & $2(1.96)$ & $13(12.7)$ \\
$\begin{array}{l}\text { Pre- } \\
\text { schoolers }\end{array}$ & $4(3.9)$ & $13(12.7)$ \\
$\begin{array}{l}\text { Early-age } \\
\text { school } \\
\text { children }\end{array}$ & $10(9.8)$ & $20(19.6)$ \\
$\begin{array}{l}\text { School } \\
\text { children }\end{array}$ & & \\
$\begin{array}{l}\text { Gender } \\
\text { Male }\end{array}$ & $1(0.98)$ & $10(9.8)$ \\
Female & & \\
\hline
\end{tabular}

used in unlicensed manner were more common in early school age children as compared to any other age categories. Prescribed unlicensed drugs were in $9.8 \%$ of school age children (11 $15 \mathrm{y}$ ), in $19.6 \%$ of early school age children (7$11 \mathrm{y})$, in $8.8 \%$ of infants $(1 \mathrm{~m}-1 \mathrm{y})$, in $12.7 \%$ of toddler $(1-3 \mathrm{y})$ and $12.7 \%$ of Preschoolers (3-6 y). Among unlicensed drugs, Milrinone was the most frequently prescribed unlicensed drug. The prescriptions of Milrinone are $24(23.52 \%)$ out of total prescriptions. Of this total, Milirone was prescribed more in males $(\mathrm{N}=14)$ than females $(\mathrm{N}=10,9.80 \%)$.

\section{Off-label drug use with respect to different age groups}

Off-label drugs were prescribed in $36.3 \%$ of total prescriptions to pediatric patients. Off-label prescribed drugs were more common in males (28.4\%) compared to females (7.8\%). A prominent difference has been observed in the frequency of off label drug administered in different age groups. Infants (19.6\%) and early School children $(9.8 \%)$ received at least one-off label drug. The different drugs which were most commonly prescribed as unlicensed and off label are presented in Table 3. Among off label drugs, Dimenhydrinate $(\mathrm{N}=21,20.0 \%)$ was the most frequently prescribed drug used in pediatrics.

\section{DISCUSSION}

Over the past few years, multisite studies performed in different settings have reported that off-label/unlicensed drug use is commonly used in the pediatric population $[6,13]$. It is because as there is no alternative to such drugs in the market or no standard treatment plan is available due to the scarcity of pediatric clinical data. As per our knowledge, it is a first study associated with the unlicensed/off-label drug utilization in pediatric patients in Lahore, Pakistan.

The overall prevalence of off label/unlicensed drug use was $5.24 \%$ which was comparable to the study performed in three European countries $(5.8 \%)$ [14]. However, the rate was much lower when compared with other studies performed in Netherland (44\%) and Germany (30\%) [15]. Another previous study reported the extent of unlicensed/off-label drug utilization in pediatrics in community practice was around $10 \%$ [16]. The prevalence rate of off-label/unlicensed drug use was higher in early-age school children (611 years) which were comparable to studies performed in Ethiopia and Germany [15,17]. A study conducted in France documented that offlabel drug is prescribed to neonates where the highest level of caution is required for safety [18].

Table 3: Unlicensed and off-label prescribed drugs

\begin{tabular}{|c|c|c|c|}
\hline Generic name & Trade Name & Patients & $\begin{array}{l}\text { Rationale /Approved for Patients older than } \\
\text { (Years) }\end{array}$ \\
\hline \multicolumn{4}{|l|}{ Unlicensed drugs } \\
\hline Inj. Milrinone & Milron & 24 & Not licensed for use in children under 18 years \\
\hline Inj. Octreotide & Sandostatin & 7 & Not licensed for use in children \\
\hline Inj. Dopamine & Dopamine & 1 & Not licensed for use in children under 12 years \\
\hline Inj. Cyclophosphamide & Cyclomide & 2 & Not licensed for use in children \\
\hline Inj. Mesna & Mesnal & 1 & Not licensed for use in children \\
\hline \multicolumn{4}{|l|}{ Off-label drugs } \\
\hline Inj. Tramadol & Tradol & 13 & Above 12 years \\
\hline Inj. Dimenhydrinate & Diemtil & 21 & Less than 01 year \\
\hline
\end{tabular}


Dimenhydrinate $(20.5 \%)$ was commonly used as off-label drug in pediatrics. Dimenhydrinate is commonly used for the treatment of vomiting and motion sickness [19]. Dimenhydrinate is often used as an off-label drug in pediatrics. A study reported that children received $85 \%$ of prescription of Dimenhydrinate in the pediatric intensive care unit (ICU) [20]. The most common unlicensed drug used was Milrinone (23.5\%). Over the last 13 years, there is an increase in the use of Milrinone in pediatric patients. A study reported that $40 \%$ of the infants experienced hypotension and thrombocytopenia [21]. Analgesics, anti-emetics and bronchodilators were the most prescribed off-label or unlicensed drugs in this study. Most of the drug categories used as off-label were ophthalmological/ otologicals, blood and blood-forming organs, cardiovascular drugs and dermatological preparations [22]. In the past 30 years, the Food and Drug Administration approved $80 \%$ of drugs with labeling disclaimer for pediatric use in United States [23]. Legislation regarding off-label or unlicensed drugs has been implemented to improve better prescribing knowledge on adequate dose, safety and efficacy of drugs [24]. $\mathrm{WHO}$ highlighted the issue regarding unlicensed/off-label drug use and adopted the Resolution "Better Medicines for Children" to improve the safety and efficacy of drug in pediatrics [15].

\section{Limitations of the study}

Since the present study was performed only in one hospital, the findings may not be representative of patients outside the hospital. This study only focused on evaluating the extent of off-label and unlicensed use of drugs in pediatrics and did not determine the benefits and adverse drug reactions (ADRs) or side effects associated with off-label/unlicensed drug utilization.

\section{CONCLUSION}

The utilization of unlicensed/off-label drugs is frequent in pediatric patients in the setting of the study. However, the quality of drug therapy is not necessarily related to its license status. Prescribers should avoid exposing their patients to unnecessary and inappropriate risk of unlicensed and off-label drugs. This study will also help to provide guidance to new researchers in clinical trials, especially on cardiovascular drugs, opioid analgesic, antiemetic and anticancer drugs. Due to the possible complications associated with off-label prescribing, such drugs should only be prescribed when the benefit is certain and when patients have exhausted all other approved options, as may be the case with rare diseases.

\section{DECLARATIONS}

\section{Acknowledgement}

The authors are thankful to the clinical pediatricians of The Children Hospital for their support in collecting data.

\section{Conflict of interest}

No conflict of interest is associated with this work.

\section{Contribution of authors}

We declare that this work was done by the authors named in this article and all liabilities pertaining to claims relating to the content of this article will be borne by the authors.

\section{Open Access}

This is an Open Access article that uses a funding model which does not charge readers or their institutions for access and distributed under the terms of the Creative Commons Attribution License (http://creativecommons.org/licenses/by/ 4.0) and the Budapest Open Access Initiative (http://www.budapestopenaccessinitiative.org/rea d), which permit unrestricted use, distribution, and reproduction in any medium, provided the original work is properly credited.

\section{REFERENCES}

1. Jong G, Vulto M, Schimmel K, Tibboel D, Anker JN. A survey of the use of off-label and unlicensed drugs in a Dutch children's hospital. Pediatrics 2001; 108(5): 10891093.

2. Nahata, Milap C. Lack of pediatric drug formulations. Pediatrics 1999; 104(Supplement 3): 607-609.

3. Santos L, Heineck I. Drug utilization study in pediatric prescriptions of a university hospital in southern Brazil: off-label, unlicensed and high-alert medications. Farm Hosp 2012; 36(4): 180-186.

4. Jain S, Bavdekar S. Gogtay N, Sadawarte P. Off-label drug use in children. Indian $J$ Pediatr 2008; 75(11): 1133-1136.

5. Organization, $W H$. Marketing authorization of pharmaceutical products with special reference to multisource (generic) products: A manual for a Drug Regulatory Authority. 1999, Geneva: World Health Organizatio.

6. Turner S, Nunn A, Fielding K, Choonara I. Adverse drug reactions to unlicensed and off-label drugs on paediatric 
wards: a prospective study. Acta Paediatr 1999; 88(9): 965-968.

7. Hughes J, Gill A, Leach $H$, Nunn A, Billingham I, Ratcliffe $J$, Thornington R, Choonara I. A prospective study of the adverse effects of midazolam on withdrawal in critically ill children. Acta Paediatr 1994; 83(11): 1194-1199.

8. Mclntyre J, Conroy S, Avery A, Corns H, Choonara I. Unlicensed and off label prescribing of drugs in general practice. Arch Dis Child 2000; 83(6): 498-501.

9. Olsson J, Kimland E, Pettersson S, Odlind V. Paediatric drug use with focus on off-label prescriptions in Swedish outpatient care-a nationwide study. Acta Paediatr 2011; 100(9): 1272-1275.

10. Hsien L, Breddemann A, Frobel A, Heusch A, Schmidt K, Läer S. Off-label drug use among hospitalised children: identifying areas with the highest need for research. Pharm World Sci 2008; 30(5): 497-502.

11. Santos D, Clavenna A, Bonati M, Coelho H. Off-label and unlicensed drug utilization in hospitalized children in Fortaleza, Brazil. Eur J Clin Pharmacol 2008; 64(11): 1111-1118.

12. Association BM, JF Committee, PSoG Britain. British national formulary. 2003: Pharmaceutical Pr.

13. Jain S, Bavdekar S, Gogtay N, Sadawarte P. Off-label drug use in children. Indian J Pediatr 2008; 75(11): 1133-1136.

14. Porta A, Esposito S, Menson E, Spyridis N, Tsolia M, Sharland M, Principi N. Off-label antibiotic use in children in three European countries. Eur J Clin Pharmacol 2010; 66(9): 919-927.

15. Tefera YG, BM Gebresillassie, AB Mekuria, TB Abebe, $D A$ Erku, $N$ Seid, HB Beshir. Off-label drug use in hospitalized children: a prospective observational study at Gondar University Referral Hospital, Northwestern
Ethiopia. Pharmacology research \& perspectives 2017; 5(2):

16. Collier J. Paediatric prescribing: using unlicensed drugs and medicines outside their licensed indications. $\mathrm{Br} \mathrm{J}$ Clin Pharmacol 1999; 48(1): 5-8.

17. Knopf H, Wolf I, Sarganas G, Zhuang W, Rascher W, Neubert A. Off-label medicine use in children and adolescents: results of a population-based study in Germany. BMC public health 2013; 13(1): 631-642.

18. Chalumeau M, Treluyer J, Salanave B, Assathiany $R$, Chéron $G$, Crocheton N, Rougeron $C$, Mares $M$, Breart $G$, Pons G. Off label and unlicensed drug use among French office based paediatricians. Arch Dis Child 2000; 83(6): 502-505.

19. Pfeil N, Uhlig U, Kostev K, Carius R, Schröder H, Kiess $W$, Uhlig $H$. Antiemetic medications in children with presumed infectious gastroenteritispharmacoepidemiology in Europe and Northern America. J Pediatr 2008; 153(5): 659-662.

20. Doherty D, Pascuet E, Ni A, Stewart P, Splinter W, Vaillancourt $R$. Off-label drug use in pediatric anesthesia and intensive care according to official and pediatric reference formularies. Can J Anaesth 2010; 57(12): 1078-1088.

21. Samiee S, Raman S, Anker J, McHutchison K, Hornik C, Clark R, P.B. Smith. Safety of milrinone use in neonatal intensive care units. Early Hum Dev 2015; 91(1): 31-35.

22. Schirm E, Tobi $H$. Risk factors for unlicensed and offlabel drug use in children outside the hospital. Pediatrics 2003; 111(2): 291-295.

23. Kauffman RE. Status of drug approval processes and regulation of medications for children. 1995.

24. Pandolfini $C, M$ Bonati. A literature review on off-label drug use in children. Eur J Pediatr 2005; 164(9): 552558 